\title{
Zika virus - A review of its existence
}

\author{
PP Gupta \\ Department of General Practice and Emergency Medicine \\ B.P. Koirala Institute of Health Sciences, Dharan, Nepal
}

\begin{abstract}
Zika virus, a flavivirus, spreads through the bite of an infected Aedes species mosquito (Ae. aegypti and Ae. albopictus). It can also be transmitted through sex with an infected man, and the virus can be passed from pregnant woman to her fetus. The most common symptoms of Zika are fever, rash, joint pain, and conjunctivitis. The illness is usually mild with symptoms lasting for several days to a week after being bitten by an infected mosquito. People usually don't get sick enough to go to the hospital, and they very rarely die of Zika. For this reason, many people might not realize they have been infected. However, Zika virus infection during pregnancy can cause a serious birth defect called microcephaly, as well as other severe fetal brain defects. Once a person has been infected, he or she is likely to be protected from future infections ${ }^{1}$.

Zika virus was first discovered in 1947 and is named after the Zika Forest in Uganda. In 1952, the first human cases of Zika were detected and since then, outbreaks of Zika have been reported in tropical Africa, Southeast Asia, and the Pacific Islands. Before 2007, at least 14 cases of Zika had

been documented, although other cases were likely to have occurred and were not reported. Because the symptoms of Zika are similar to those of many other diseases, many cases may not have been recognized ${ }^{1}$. In May 2015, the Pan American Health Organization (PAHO) issued an alert regarding the first confirmed Zika virus infection in Brazil. On February 1, 2016, the World Health Organization (WHO) declared Zika virus a Public Health Emergency of International Concern (PHEIC). Local transmission has also been reported in many other countries and territories. Zika virus will likely continue to spread to new areas ${ }^{1}$.

Zika virus is an intensely neurotropic virus that particularly targets neural progenitorcells but also - to a lesser extent - neuronal cells in all stages of maturity. Viral cerebritis can disrupt cerebral embryogenesis and result in microcephaly and other neurological abnormalities $^{2}$. Zika virus has been isolated from the brains and cerebrospinal fluid of neonates born with congenital microcephaly and identified in the placental tissue of mothers who had had clinical symptoms consistent with Zika virus infection during
\end{abstract}


their pregnancies ${ }^{3-5}$. The spatiotemporal association of cases of microcephaly with the Zika virus outbreak and the evidence emerging from case reports and epidemiologic studies, has led to a strong scientific consensus that Zika virus is implicated in congenital abnormalities ${ }^{6-7}$.

Existing evidence and unpublished data shared with $\mathrm{WHO}$ highlight the wider range of congenital abnormalities probably associated with the acquisition of Zika virus infection in utero. In addition to microcephaly, other manifestations include craniofacial disproportion, spasticity, seizures, irritability and brainstem dysfunction including feeding difficulties, ocular abnormalities and findings on neuroimaging such as calcifications, cortical disorders and ventriculomegaly ${ }^{3-6,8-10}$. Similar to other infections acquired in utero, cases range in severity; some babies have been reported to have neurological abnormalities with a normal head circumference. Preliminary data from Colombia and Panama also suggest that the genitourinary, cardiac and digestive systems can be affected (Pilar Ramon-Pardo, unpublished data).The current incidence of Zika virus infection in the Americas is difficult to gauge because the symptoms are nonspecific and generally mild, laboratory diagnosis is not uniformly available, and flavivirus antibody cross-reactivity complicates serologic assessment in areas in which dengue is endemic. Nevertheless, given the historically high incidence of dengue in the region and the recent experience with the chikungunya virus in the Americas, millions of Zika virus infections should be expected as the virus continues to spread $^{11-12}$.If Brazil serves as a "warning bell" for the rest of Latin America and the Caribbean, substantial numbers of infants with microcephaly and other adverse pregnancy outcomes could be identified in the upcoming months. The potential burden of illness from Guillain-Barré syndrome is hard to assess, given the difficulties with serologic diagnosis in areas where dengue is endemic and the paucity of published data on current incidence.

The underlying reasons for the emergence of Zika virus in the past decade are unknown. Recent global increases in the incidence and spread of dengue, chikungunya, and now Zika virus - all with $A$. aegypti as the primary vector - suggest common underlying mechanisms for their emergence, such as globalization and urbanization ${ }^{11,13,15}$. Other possible explanations include viral mutations affecting transmission or virulence and viral introduction to previously unexposed populations leading to epidemic spread. Further research will be required to determine whether the recently observed associations with adverse birth outcomes and GuillainBarré syndrome simply reflect an increased 
incidence of infection or whether they result from a change in viral virulence. In areas of Africa and Asia where Zika virus is endemic, the incidence of infection, whether outbreaks will occur, and the reason for the previous lack of recorded cases of adverse pregnancy outcomes or Guillain-Barré syndrome are unknown. It is possible that many exposures occur in children, in whom Guillain-Barré syndrome may be less likely to develop and who would later be immune to infections during pregnancy.

The long-term outlook with regard to the current Zika virus outbreak in the Americas is uncertain. Herd immunity sufficient to slow further transmission will undoubtedly occur, although this will not obviate the need for immediate and long-term prevention and control strategies. Whether and where the virus becomes endemic and whether an enzootic transmission cycle will develop somewhere in the Americas are matters of conjecture, but they are of considerable importance for the long-term development and sustainability of countermeasures, such as a Zika virus vaccine.

Zika virus disease is usually mild and requires no specific treatment.People sick with Zika virus should get plenty of rest, drink enough fluids, and treat pain and fever with common medicines. If symptoms worsen, they should seek medical care and advice. There is currently no vaccine available.
Protection against mosquito bites is a key measure to prevent Zika virus infection. This can be done by wearing clothes (preferably light-coloured) that cover as much of the body as possible; using physical barriers such as window screens or closing doors and windows; sleeping under mosquito nets; and using insect repellent containing Directed Energy Eod Tool (DEET), IR3535 or icaridin according to the product label instructions. Special attention and help should be given to those who may not be able to protect themselves adequately, such as young children, the sick or elderly. Travellers and those living in affected areas should take the basic precautions described above to protect themselves from mosquito bites.

It is important to cover, empty or clean potential mosquito breeding sites in and around houses such as buckets, drums, pots, gutters, and used tyres. Communities should support local government efforts to reduce mosquitoes in their locality. Health authorities may also advise that spraying of insecticides be carried out ${ }^{16}$.

Sexual transmission of Zika virus has been documented in several different countries. To reduce the risk of sexual transmission and potential pregnancy complications related to Zika virus infection, the sexual partners of pregnant women, living in or returning from areas where local transmission of Zika virus occurs should practice safer sex (including 
using condoms) or abstain from sexual activity throughout the pregnancy ${ }^{16}$.

People living in areas where local transmission of Zika virus occurs should also practice safer sex or abstain from sexual activity. In addition, people returning from areas where local transmission of Zika virus occurs should adopt safer sexual practices or abstain from sex for at least 8 weeks after their return, even if they don't have symptoms. If men experience Zika virus symptoms they should adopt safer sexual practices or consider abstinence for at least 6 months. Those planning a pregnancy should wait at least 8 weeks before trying to conceive if no symptoms of Zika virus infection appear, or 6 months if one or both members of the couple are symptomatic16.

WHO is supporting countries to control Zika virus disease by taking actions outlined in the "Zika Strategic Response Framework"16.

a. Define and prioritize research into Zika virus disease by convening experts and partners.

b. Enhance surveillance of Zika virus and potential complications.

c. Strengthen capacity in risk communication to engage communities to better understand risks associated with Zika virus.

d. Strengthen the capacity of laboratories to detect the virus. e. Support health authorities to implement vector control strategies aimed at reducing Aedes mosquito populations. recommendations for the clinical care and follow-up of people with complications related to Zika virus infection, in collaboration with experts and other health agencies.

\section{References}

1. About Zika Virus. www.cdc.gov. 2016 [cited 27 June 2016]. Available from: https://www.cdc.gov/aboutzikavirus

2. Tang H, Hammack C, Ogden SC, Wen Z, Qian X, Li Y, et al. Zika virus infects human cortical neural progenitors and attenuates their growth. Cell Stem Cell. 2016 May 5; 18(5):587-90. http://dx.doi.org/10.1016/j.stem.2016.02 .016 pmid: 26952870

3. Driggers RW, Ho CY, Korhonen EM, Kuivanen S, Jääskeläinen AJ, Smura T, etal. Zika virus infection with prolonged maternal viremia and fetal brain abnormalities. $\mathrm{N}$ Engl J Med. 2016:30;NEJMoa1601824.

http://dx.doi.org/10.1056/NEJMoa16018 24 pmid: 27028667.

4. Brasil P, Pereira JP Jr, Raja Gabaglia C, Damasceno L, Wakimoto M, Ribeiro Nogueira RM, et al. Zika virus infection in pregnant women in Rio de Janeiro preliminary report. N Engl J Med. 2016 
Mar

4;NEJMoa1602412.

http://dx.doi.org/10.1056/NEJMoa16024

12 pmid: 26943629.

5. Mlakar J, Korva M, Tul N, Popović M, Poljšak-Prijatelj M, Mraz J, et al. Zika virus associated with microcephaly. $\mathrm{N}$ Engl J Med. 2016:10;374(10):951-8. http://dx.doi.org/10.1056/NEJMoa16006 51 pmid: 26862926.

6. Cauchemez S, Besnard M, Bompard P, Dub T, Guillemette-Artur P, EyrolleGuignot D, et al. Association between Zika virus and microcephaly in French Polynesia, 2013-15: a retrospective study. Lancet. 2016:15;S01406736(16)00651-6. pmid: 26993883.

7. SA Rasmussen, Jamieson DJ, Honein MA, Petersen LR. Zika virus and birth defects- reviewing the evidence for causality. N Engl J Med. 2016 Apr 13.

8. Besnard $M$, Eyrolle- Guignot D, Guillemette-Artur P, Lastère S, BostBezeaud F, Marcelis L, et al. Congenital cerebral malformations and dysfunction in fetuses and newborns following the 2013 to 2014 Zika virus epidemic in French Polynesia. Euro Surveill. 2016: $31 ; 21(13): 30181$.

http://dx.doi.org/10.2807/1560-

7917.ES.2016.21.13.30181 pmid: 27063794.

9. De Paula Freitas B, de Oliveira Dias JR, Prazeres J, Sacramento GA, Ko Al,
Maia $\mathrm{M}$, et al. Ocular findings in infants with microcephaly associated with presumed Zika virus congenital infection in Salvador, Brazil. JAMA Ophthalmol. $2016 \quad$ Feb 9; http://dx.doi.org/10.1001/jamaophthalm ol.2016.0267 pmid: 26865554.

10. Miranda-Filho DB, Martelli CM, Ximenes RA, Araújo TV, Rocha MA, Ramos RC, et al. Initial Description of the presumed congenital Zika syndrome. Am J Public Health. 2016;106(4):598-600.

http://dx.doi.org/10.2105/AJPH.2016.30 3115 pmid: 26959258.

11. Musso D, Cao-Lormeau VM, Gubler DJ. Zika virus: following the path of dengue and chikungunya? Lancet 2015; 386:243-244.

12. Bhatt S, Gething PW, Brady OJ, et al. The global distribution and burden of dengue. Nature 2013; 496:504-507.

13. Weaver SC, Lecuit M. Chikungunya virus and the global spread of a mosquito-borne disease. $\mathrm{N}$ Engl J Med 2015; 372:1231-1239.

14. Leparc-Goffart I, Nougairede A, Cassadou S, Prat C, de Lamballerie X. Chikungunya in the Americas. Lancet 2014; 383:514-514.

15. Wilder-Smith A, Gubler DJ. Geographic expansion of dengue: the impact of 
international travel. Med Clin North Am 2008; 92:1377-1390.

16. World Health Organisation. Zika Virus. 2016. Available from: https://www.who.int
17. Prepare recommendations for the clinical care and follow-up of people with complications related to Zika virus infection, in collaboration with experts and other health agencies. 